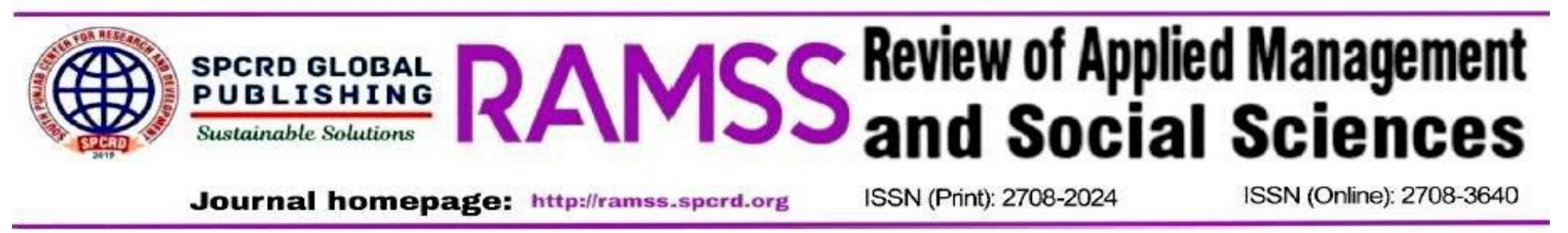

\title{
Students' Political Parties and Higher Education Institutes: Evidence From Pakistani Universities
}

${ }^{a}$ Najam ul Kashif, ${ }^{b}$ Furrukh Bashir, ${ }^{\mathrm{c}}$ Rashid Ahmad

${ }^{a}$ Assistant Professor, Department of Education, The Islamia University of Bahawalpur

Email: drnajam.ulkashif@iub.edu.pk

${ }^{\mathrm{b}}$ Assistant Professor, School of Economics, Bahauddin Zakariya University, Multan, Pakistan

Email: furrukh@bzu.edu.pk

${ }^{c}$ Assistant Professor, School of Economics, Bahauddin Zakariya University, Multan, Pakistan

Email: rashidahmad@bzu.edu.pk

\begin{tabular}{|c|c|}
\hline ART & ABSTRACT \\
\hline & \multirow{10}{*}{$\begin{array}{l}\text { Students' political parties are allowed in the universities of Pakistan. But } \\
\text { what is the influence of these political parties on the university students } \\
\text { is a very critical issue. Through media teachers, parents, society } \\
\text { members and educationists are opposing these parties. The purpose of } \\
\text { this study was to find out the impact of these parties on the university } \\
\text { students. Questionnaire and observation sheet are the tools of the } \\
\text { research. This study was descriptive in nature and mix method } \\
\text { (triangulation) approach was used. Findings of the study indicated that } \\
\text { the subjects of the study (University Students, Parents and Teachers) } \\
\text { were strongly against the students' political parties and their activities. } \\
\text { The results were also indicating that criminal damage, injuries, deaths } \\
\text { are at top in the presence of these political parties in the universities. } \\
\text { Some other interesting findings were also drawn about the political } \\
\text { parties'practise in the universities. }\end{array}$} \\
\hline Accep & \\
\hline Available Onlin & \\
\hline & \\
\hline Political Parties, Unive & \\
\hline Students, Criminal Da & \\
\hline & \\
\hline JEL & \\
\hline$I 21$ & \\
\hline & \\
\hline
\end{tabular}

(C) 2021 The authors. Published by SPCRD Global Publishing. This is an open-access article under the Creative Commons Attribution-

NonCommercial 4.0

Corresponding author's email address: furrukh@bzu.edu.pk

\section{Introduction}

Pakistan being the multicultural state as well as its boarders is attached with multi civilized countries. If two biggest populated countries are its neighbours at the same time politically and at international level two challenging states for the world are also the neighbours of Pakistan. In the present scenario, Pakistan is the big part of war against terrorism. In short Pakistan plays a vital role in the South Asia. But uncertain conditions at the boarders and international and national interference have damaged the overall image of Pakistan. Pakistan is now of more than 65 years old but dictators have ruled here more than half years of its life. Democracy brutally crushed here in the past. But the question arises that what why democracy brutally treated? There are may be many 
reasons and answers behind this question but here it is tried to explain the role of the political parties. Pakistan may be one of the few states of the world in which the main political parties of the nation are legally authorized to work in the educational institutes. In the past, Muslim Students Federation (MSF) was the only students' political party in the universities when Pakistan came into being. Later in 1950, students of Dow Medical College, Karachi met as they have some complaints against the MSF and they established Democratic Students Federation (DSF) and after this till at the moment many students' political, religious and social parties are working in universities (Paracha, 2008). According to an experienced person among student union leaders that in 1970s was the first seen violence phenomenon in the university campuses (Sahi, 2007). And the situation was getting worst in the Martial Law of general Zia. And after this the Jihad of Afghan brought the Kalashnikov culture in the higher educational institutes and later on the open exhibition of arms was also observed. To stop this growing arm culture in the public universities, police substations (police chaukis) are established within the universities. Now, the public universities are giving not a different look of the underworld life where law and crime are at front, in universities law and students' parties. It is another very astonishing fact that most veteran students' political parties' workers and leaders blame religious political parties to bring violence and arm culture in the universities (Sahi, 2007).

According to Islamic Jamiat e Tulba (IJT), a famous and well known religious political students' party in the higher educational institutes of Pakistan, 151 students' violence cases were recorded. The record highlighted that 13 young students who are not only the future of nation but also the bright dreams of their families were brutally pushed in the mouth of death. About 250 students were paralysed due to these students' violence cases. As a result, higher education institutes expelled 110 students to control such violence but on the other side, these expelled students deprived from the higher education also. Things can't stop there, Law Enforcement Agencies also called for peace making in the institutes and as a result they arrested about 800 students in different allegations out which are some were under the terrorism allegations in the period of 1947 to 1984 (Sahi, 2007). An astonishing fact was quoted again by Sahi (2007) that in this period, students' politics was banned in the educational institutes. From 1984 to 2004, the record highlighted that 165 young students who are not only the future of nation but also the bright dreams of their families were brutally pushed in the mouth of death. About 1210 students were paralysed due to these students' violence cases. As a result, higher education institutes expelled 985 students to control such violence but on the other side, these expelled students deprived from the higher education also. Things can't stop there, Law Enforcement Agencies also called for peace making in the institutes and as a result they arrested about 7235 students in different allegations out which are some were under the terrorism allegations.

The politics of political or religious parties in the universities use the educated youth for their internal and hidden purposes and try to disturb the academic environment of the universities, just for showing their power which are not looking parallel to the objectives of the university education. The above-mentioned figures can explain the role of the students' parties in the higher education institutes. Educational institutes are the place of learning and peace, but the figures and facts are not showing the true picture of higher educational institutes in the scenario of learning and peace (Akhtar, 2007 \& Nelson, 2009).

University students are the most sensitive creations, and they are in the age where everything is going for the future. The educational life is at its peak and professional life is just going to start. 
Future planning are the hot issues in different contexts among university students. In such scenario, the environment of the university plays a vital role. But the political parties and student unions become the elements of constant source of appealing for the young minds.

In the present scenario of Pakistan, when international and national media is highlighting the disturbing issue of extremism, it looks very important to take a glimpse of the educational institutes. In contrast with the developed countries, the pressure groups of national political parties, religious parties and local governing bodies are badly affecting the educational environment. Universities as the higher formal institutes of education, becomes the residential place of these pressure groups whose are continuously affecting the learning environment. Although, it will take time to realise the present working situation of universities under such crucial circumstances, but it is the need of the time that such pressure groups should be eliminated from the educational institutes. This kind of the studies are rarely done in Pakistan.

Current study was aimed at to highlight the students pressure groups' role in the educational environment of universities. To achieve the aim, following three research questions are focuses.

1. What is the role of the students' political parties in the universities?

2. Do students' political parties play any constructive role for the university students?

3. How these students' political parties are becoming the pressure groups in the universities to disturb the educational environment?

\section{Research Methodology:}

Political parties' involvement in the academic institutions and especially at Higher Education Level is not taking as a positive activity by the civil society members. To check such kind of activity, this study was designed. Best and Kahn (2006), opined that to study an existing issue or problem, getting views on the existing situation and keeping an eye on the spreading effects of a social phenomenon, descriptive research design is best. As the current study is also focused on a social phenomenon of political groups' involvement in the higher education institutes, so descriptive research design was adopted to fulfil the needs of the study. This study focused on the prevailing situation of political groups in the higher education institutes and this study observed this phenomenon by employing QUAL-QUAN approach. At the same time, two different research tools were used to fulfil the needs of the study. The first tool was questionnaire and the second one was observation sheet.

There are three subjects of the study: university students, parents of the university students and the university teachers. For all these subjects of the study, three questionnaires were developed at five-point Likert Scale from strongly agreed to strongly disagreed. The researcher has also adopted an observation sheet. Observation sheet was employed to observe the eventual intensity in the different places in the different universities. Observation sheet was also developed at four-point scale from never to frequently. Nine different places were observed by the researcher and his team. These places are under the boundary wall of the targeted university. The targeted nine points of the universities were: Libraries, canteens/cafeterias, classrooms, corridors, university bus stands, washrooms, university buses, university grassy lawns and sitting areas. The validity and reliability of the research tools was checked with the expert opinions and through the pilot study. 
Figure1: Evidence Observation Areas of Universities and Students' Political Groups
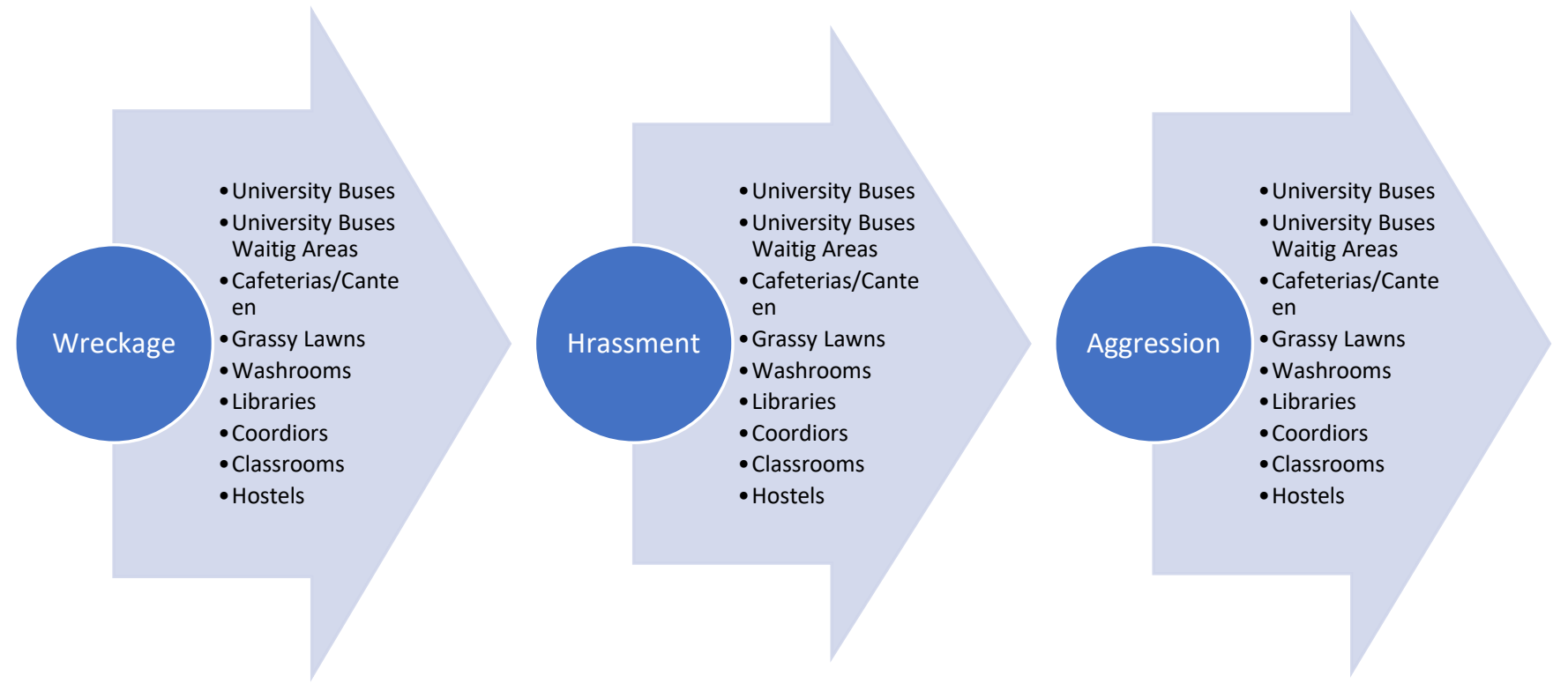

The sample was based on the 11 public sector general universities of Pakistan. These universities were selected by adopting multistage sampling technique. In the first stage, as per division of Pakistan; two public sector universities from four provinces and from three territories i.e., Kashmir, Gilgit and Islamabad Capital Territory, one public sector university was selected randomly. In the second stage, from each university, 20 students, five university students' parents as well as five university teachers were targeted as sample. The researcher used pseudonyms to all the universities for example, University A, University B etc.

\section{Findings and Discussion:}

The research tools are based on four factors. These factors are harassment, university students' political parties, aggression, and wreckage. Each factor with their findings is discussed here in detail.

Table No.1: Percentage Score

\begin{tabular}{|l|l|c|c|c|c|c|c|c|c|c|}
\hline \multirow{2}{*}{$\begin{array}{c}\text { S. } \\
\text { No. }\end{array}$} & \multicolumn{1}{|c|}{ Target Areas } & \multicolumn{3}{|c|}{ Harassment } & \multicolumn{3}{c|}{ Wreckage } & \multicolumn{3}{c|}{ Aggression } \\
\cline { 2 - 10 } & & S. & T. & P. & S. & T. & P. & S. & T. & P. \\
\hline $\mathbf{1}$ & University Buses & $78 \%$ & $63 \%$ & $54 \%$ & $86 \%$ & $71 \%$ & $59 \%$ & $89 \%$ & $56 \%$ & $34 \%$ \\
\hline $\mathbf{2}$ & $\begin{array}{l}\text { University Buses } \\
\text { Waiting Areas }\end{array}$ & $73 \%$ & $48 \%$ & $51 \%$ & $54 \%$ & $44 \%$ & $35 \%$ & $48 \%$ & $36 \%$ & $41 \%$ \\
\hline 3 & Cafeterias/Canteen & $69 \%$ & $76 \%$ & $48 \%$ & $78 \%$ & $73 \%$ & $76 \%$ & $65 \%$ & $68 \%$ & $38 \%$ \\
\hline 4 & Grassy Lawns & $51 \%$ & $65 \%$ & $37 \%$ & $45 \%$ & $34 \%$ & $39 \%$ & $46 \%$ & $65 \%$ & $56 \%$ \\
\hline 5 & Washrooms & $39 \%$ & $47 \%$ & $25 \%$ & $34 \%$ & $23 \%$ & $31 \%$ & $62 \%$ & $48 \%$ & $28 \%$ \\
\hline 6 & Libraries & $35 \%$ & $29 \%$ & $28 \%$ & $37 \%$ & $29 \%$ & $28 \%$ & $54 \%$ & $39 \%$ & $31 \%$ \\
\hline 7 & Corridors & $68 \%$ & $60 \%$ & $46 \%$ & $36 \%$ & $37 \%$ & $35 \%$ & $75 \%$ & $67 \%$ & $45 \%$ \\
\hline 8 & Classrooms & $89 \%$ & $48 \%$ & $35 \%$ & $77 \%$ & $66 \%$ & $54 \%$ & $82 \%$ & $57 \%$ & $56 \%$ \\
\hline 9 & Hostels & $41 \%$ & $56 \%$ & $67 \%$ & $68 \%$ & $82 \%$ & $67 \%$ & $85 \%$ & $68 \%$ & $74 \%$ \\
\hline
\end{tabular}


Review of Applied Management and Social Sciences (RAMSS) Vol. 4, (4) 2021, 889 - 896

In the table No. 1, there is a contrast comparison among harassment, wreckage, and aggression at nine different places in the university boundary by the three major stakeholders of universities i.e., Students (P.), Teachers (T.), and Parents (P.). Results shows that harassment, wreckage, and aggressions are more likely to be observed in university buses, canteens/cafeterias, corridors, classrooms and hostels.

\subsection{Harassment}

In Pakistan, the role of the students' political parties or the students' unions is totally different as compare to the other parts of the world (Abbasi, 2014). Since last three decades, it is noted by different institutions and reporting agencies that the cases of harassment in general and cases of sexual harassment in specific is increased many times. The enhancement of the sexual harassment in the civil society is on one side whereas the heightening of sexual harassment cases at academic institutes and especially at higher educational institutes is a dilemma (John \& Michael, 2005; Nancy, Susan, \& John, 2003). This is not a dilemma of a single nation, but it is spreading from developed countries to third world countries. In many cases and in many countries, this dilemma is reached in a very critical situation. After different kind of punishment laws, now different countries have made the plenty of death (in few cases). Another astonishing element in the harassment cases is, that it is not staying or confined to opposite gender cases, even homosexual harassment cases are also enhanced. Higher education institutes where students come at their peak youth age, and the atmosphere of co-education heightening these cases. Exclusively, at higher education institutes, where youth and free mixing of both genders is officially allowed, to stop it is a very difficult task.

Keeping in mind the same scenario, when the cases of harassment were observed in the different targeted universities, it came to notice that in majority of cases, seniors harassed juniors in different perspectives and take the edge of their seniority. As well as small groups and individuals are also harassed by big groups or group of vagabond students. Students and especially the female students have expressed their views and it was also come in through observations that mostly students are harassed cafeterias or canteens in the A, C, F, G and H Universities. Even it is also come to know that shouting and calling the female and male students with bad names and manners on these places is common by the students' political groups. Students and especially the female students were not comfortable while sitting in cafeterias, canteens, grassy lawns and walking in the corridors. It is also observed that such mentioned places don't have individuals and couples in a big number. So, separate points for female students are observable in these universities but the issue of male students remained un-addressable. In the university G, harassment cases were observed at university buses' stands, in the university buses as well as in the grassy lawns and grounds. Such a tensed environment is creating problems for those students who want group study and especially if the group is based on heterogenous gender. Here, not only the students' political groups are creating problems for them but also the so-called religious groups are problem creators for the peaceful environment of the universities. It is also observed that to control such kind of activities, university $\mathrm{C}$ has fixed different days for library usage for both genders as well as different waiting areas for university buses within the parenthesis of the universities. To verify these observation, related questions were also asked from the three major subjects of study i.e., university students, their parents and university teachers. Results indicated that about $70 \%$ university students and out of which 90\% female university students; 86\% university teachers and 43\% parents of the university students are agreeing that the issue of harassment and especially the sexual harassment is in their notices. A father of the university female student said that we know it very well, but we don't have any other choice if we want to give higher education to our siblings. 


\subsection{University Students' Political Groups}

Higher Educational Institutes are considered as the last step of academia and first step towards the practical life. Keeping in mind, such scenarios and to aware the youth with the national and international policies and governing patterns, different countries have allowed the political groups to establish their students' wings in the higher education institutes (Farrington, 2005). To develop a rational thinking among the university students, it is also expecting from them that while taking any decision or doing any job, they must be aware of its good and bad results. From diverse areas of the country, students come to public sector universities and especially in the general category public sector universities where they have the option to get admission from Pharmacy to Engineering fields, in different disciplines of Natural Sciences to Social Sciences, as well as from Languages to Arts. After getting several students in different disciplines of academia, in the full swing of youth, students get the chances of free mixing with opposite genders, no restriction of creed and colour, language and family background, no social or economic barrier is there to stop the youth from meeting each other in different places. On the name of freedom, and fear from the youth, no proper check and balance from university students' parents to university teachers and from university administration to civil society members. Such are the best circumstances for the students' political parties, and they use it in a very skilful way. The university teachers' questionnaire results also in second the researchers' observation and check list that political parties aren't playing any constructive or positive role for the university students and their percentage is about $80 \%$. At the same time 78 percent parents of the university students and 69 percent university students are also have the opinion in nominating the students' political parties to spoil the environment of the university.

\subsection{Aggression}

Youth and aggression are interconnected in different aspects. Youth take each and everything as a matter of their ego and as a result, they fix in different bad situations (LopesNeto, 2005). The easiest way to get fame, lies under the showing of power and threat to your fellows, juniors, and others (Fekkes, Pjipers, Veroove-Vanhorick, 2005). Aggressive behaviour is the utmost subject of great concern as well as the social behaviour. Many social behaviours i.e., disturbing others, rebelliousness, hostile attitude, pinching others by pushing, snubbing and hitting are some examples of aggressive behaviours students from different universities opined that aggressive behaviour where is a part of human cognition is also a identical mutual phenomenon among university students (Eddy \& Reid, 2002 \& Duncan, Michael, \& Jack, 2002). Different aspects of aggression were asked by the university students and for the cross validation some items related to the university, asked by university teachers and some items related to personal life were asked by the parents of the university students. Aggression is the backbone of all kind of quarrels and fights. Aggression leads to fights and which ultimately directed towards injuries and even killing. In the same context Sahi in 2007 reported that there were 525 violence cases were recorded from 1984 to 2004 in the higher education institutes. In these violence cases, more than 160 students were killed, more than 1200 students were severely injured, about 1000 students were forcefully expelled from the institutions and law enforcement agencies have arrested and put in prison on different acts about 7250 students. Given figures by Sahi (2007) are not normal figures, more than 160 families lost their young children who were in universities for higher education. Their families consider them as their future as well as bright future of the nation. When the extreme of aggression gives the results in injury or death or struck off the name from the educational institutes, which are on record. What are the results of teasing or pressurizing others, is a big question? As there is no record that by pressurizing teachers what type of favours students are getting? And like many other questions are remained addressable. 


\subsection{Wreckage}

Wreckage or the breaking or damaging of public property is another Wreckage is another side effect of students' political group in the higher education institutes. Misuse of power by the rotten egg students, and to show their aggression by damaging or breaking the public or university property is looking a common phenomenon in the universities. Given figures by Sahi (2007) also give a thought the in more than 500 students' violence cases where thousand of students lost their precious lives what about the place where such incidents were happened. Wreckage, damaging or breaking of university property is missed in this report. But if we just give a look in the recent incidents which were happened in the universities like in the capital of Pakistan, there is a wellknown university where two groups were continuously in quarrel since last five years; in the metropolitan university of Baluchistan, wreckage is reported in Billions, in the last few years; in the Metropolitan university of Sindh, there are Police Chokies and check posts as well as rangers are also have their duties to stop the wreckage and fighting. Such incidents and figures of different universities are highlighting the poor conditions of their institutions.

\section{Conclusion}

On the basis of above findings and discussion, it can be very easily sketch out the true picture of political parties and their activities in the universities. It's not a sense that students' political parties or political groups were involved in the same practices in the past. So, they should be banned, and rotten eggs should be banned to enter in the universities. Security measures should be enhanced and counselling of newcomer students should be held on regular basses. But the modern age, so called check and balance on university students and the freedom beyond the limits have created such atmosphere in the universities.

\section{Recommendations}

On the basis of above findings and discussion, following recommendation were set;

- Political parties must be banned in the universities.

- Those who destroy the educational environment of the universities must be treated with iron hands.

- Political interference in the universities must be zero.

- Political party interference should be banned, and students' council should be encouraged.

- Students' council should be a part of management and give advises to make atmosphere better for learning activities.

\section{References}

Abbasi, I., (2014), http://www.thenews.com.pk/article-144647-Student-groups-clash-at-BZU-in-Multan--

Akhtar, A. S., (2007). Campus or Politics. . http://jang.com.pk/thenews/jun2007-weekly/nos-17-062007/spr.htm (accessed on June 13, 2011)

Best, W. J. \& Kahn, V. J. (2006), Research in Education, 9th Edition, New Delhi, Pearson Prentice hall.

Duncan, B. C., Michael, V., \& Jack, C., (2002) Childhood Anti Social Behaviour and Adolescent Alcohol use Disorder

Eddy, M., Reid, J., (2002), Adolescent Children of Incarcerated Parents: A Developmental perspective, U. S. A., Publication of the conference "From Prison to Home". January, 30 to 31, 2002

Farrington, D. (2005). Childhood origins of Antisocial Behavior. Clinical Psychology and Psychotherapy, Volume 12,

Fekkes, M., Pijpers, F.I., Verloove-Vanhorick, S.P., (2005). Bullying: who does what, when and 
where? Involvement of children, teachers and parents in bullying behavior. Health Education Research. 20

John B., and Michael, F. D., (2005). Assualt on the professions and the restructuring of Academic and Professional identities: a Bernsteinian analysis: British Journal of Sociology of Education, Volume 26(2).

Lopes Neto, A.A. (2005) Bullying-aggressive behaviour among students. Journal de Pedatria. 2005;81(5Suppl): 164-17

Nelson, M. J., (2009). Religion, Politics and the Modern University in Pakistan and Bangladesh. The national Bureau of Asian Research. N.B.R. Project report.

Paracha, N. F., (2008). Student Politics in Pakistan: A celebration, lament and history. http://nadeemfparacha.wordpress.com/student-politics-in-pakistan-a-celebration-lamenthistory (accessed on June 13, 2021)

Remus, I., Nancy H., Susan S., and Stibal J., (2003). Reported Incidence rates of work related sexual harassment in the United States: Using Meta Analysis to explain reported rate disparities. Personnel Psychology 2003;56:607-631

Rubin, A., and Babbie, E., (2001), Research Methods for Social Work, 4th Edition, USA; Brooks/Cole Thomson Learning

Sahi, A., (2007). Violence per se. http://jang.com.pk/thenews/jun2007-weekly/nos-17-06-2007/spr.htm (accessed on June 13, 2021)

\section{Appendix-1}

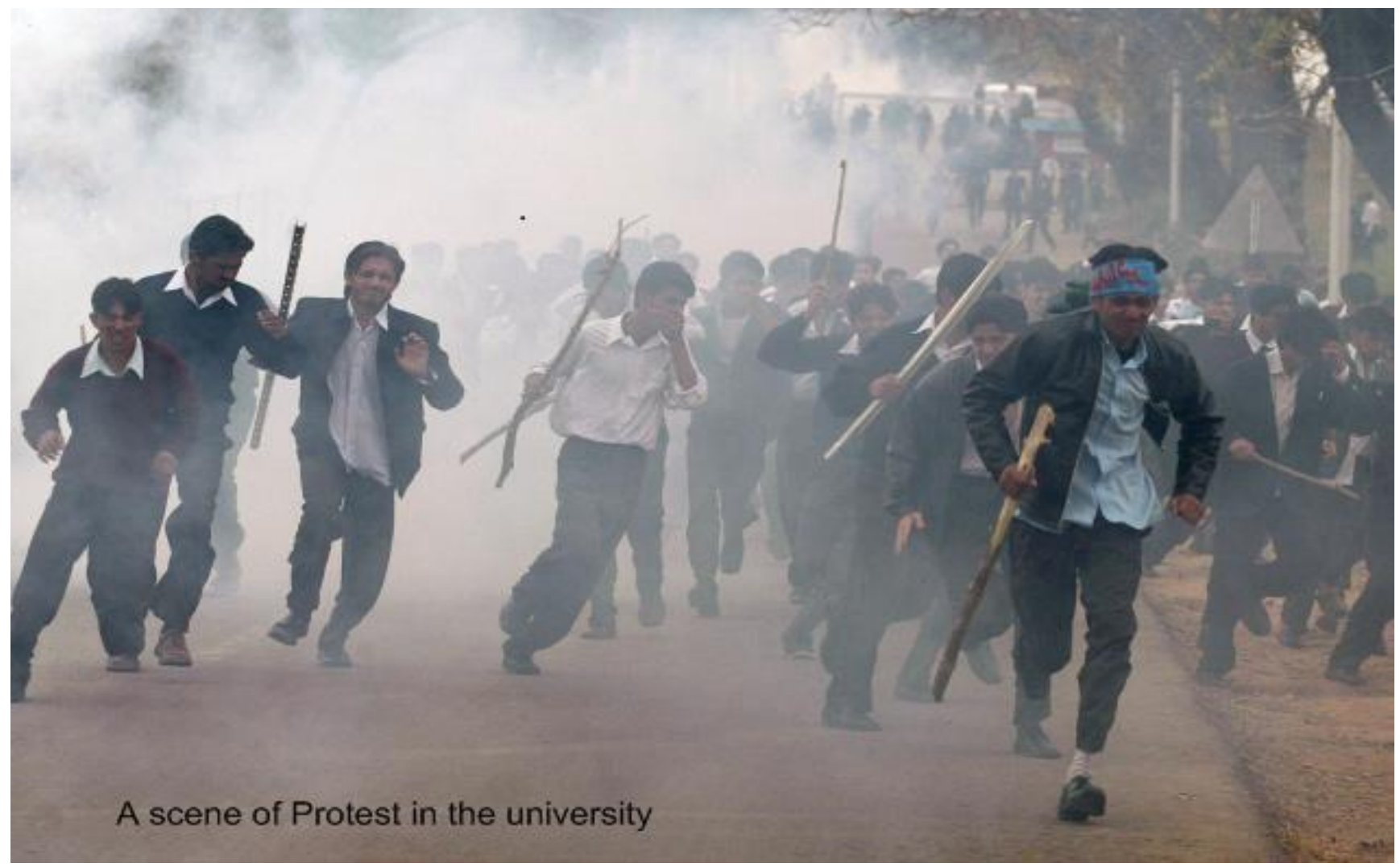

